\title{
IDENTIFIKASI KELAYAKAN CHAINSAW PADA KEGIATAN PENEBANGAN UNTUK KESELAMATAN DAN KESEHATAN PEKERJA DI PT. PERAWANG SUKSES PERKASA INDUSTRI (PSPI)
}

\section{Identification of the Feasibility of Chainsaw in Logging Activities for Worker Safety and Health in PT. Perawang Sukses Perkasa Industri (PSPI)}

\author{
Ika Lestari $^{1}$, Emy Sadjati ${ }^{1}$, Ambar Tri Ratnaningsih ${ }^{1}$ \\ ${ }^{1}$ Staff pengajar di Program Studi Kehutanan, Fakultas Kehutanan, Universitas Lancang Kuning , Jalan \\ Yos Sudarso Km 8, Rumbai, Pekanbaru
}

Email: lestariika32@gmail.com, emymnhunilak@gmail.com, ambar@unilak.ac.id

Diterima: 27 Mei 2021, Direvisi: 31 Mei 2021, Disetujui: 21 Juli 2021

DOI: $10.31849 /$ forestra.v16i2.6878

\begin{abstract}
Using chainsaws in logging activities, operators need to ensure that the chainsaws used are fit for use and comply with predetermined standards, particularly in accordance with operational standards that ensure safety and health while working. Modifying the chainsaw is not justified, because it will make the operator unsafe situation. PT. PSPI is one of industrial plantation forest companies in Riau Province which currently produces timber forest products for pulp and paper raw materials. Logging activies in PT. PSPI is still using chainsaw for cutting tree. In logging activities using chainsaws, companies and operators need to ensure that the chainsaws to be used are in proper condition in accordance with predetermined operational standards, the aim to ensure operator stay safety and health while working. The result of this research in identifying chainsaw machines in logging activities carried out at PT. PSPI used 4 indicators, specification of machine chainsaw, the condition of chainsaw, the modification and the age of the chainsaw. Chainsaw is using operators at PT. PSPI is categorized as feasibility enough for use in logging activities with a score of 70. Exhaust modification on chainsaw engines cannot be justified and is expected not to be used in logging activities, and should be maintenance to a predetermined standard.
\end{abstract}

Keywords: Chainsaw, HTI, feasibility, logging activities, OSH.

\begin{abstract}
ABSTRAK
Pada kegiatan penebangan menggunakan chainsaw, operator perlu memastikan bahwa chainsaw yang digunakan layak untuk dipakai dan sesuai dengan standar yang telah ditentukan, khususnya sesuai dengan
\end{abstract}

Ika Lestari, Emy Sadjati, Ambar Tri R., / Wahana Forestra: Jurnal Kehutanan Vol. 16 No. 02/2021 
standar operasional yang menjamin keselamatan dan kesehatan pada saat bekerja. Melakukan modifikasi pada chainsaw adalah tindakan yang tidak dibenarkan, karena akan membuat operator dalam keadaan tidak aman. PT. PSPI merupakan salah satu anak perusahaan HTI di Provinsi Riau yang saat ini berproduksi pada hasil hutan kayu untuk bahan baku pulp dan paper. Kegiatan penebangan pohon di perusahaan ini masih menggunakan mesin chainsaw sebagai alat pemanenan. Dalam kegiatan penebangan menggunakan chainsaw, perusahaan dan operator perlu memastikan bahwa chainsaw yang akan digunakan layak dengan kondisi yang sesuai dengan standar operasional yang telah ditentukan, yang bertujuan untuk menjamin keselamatan dan kesehatan operator pada saat bekerja. Penelitian identifikasi kelayakan mesin chainsaw dalam kegiatan penebangan yang dilaksanakan di PT. PSPI menggunakan 4 indikator yakni tipe alat, kondisi alat, modifikasi dan umur alat. Alat penebangan yang digunakan oleh operator chainsaw di PT. PSPI masuk dalam kategori cukup layak untuk digunakan dalam kegiatan penebangan dengan skor 70. Modifikasi knalpot pada mesin chainsaw tidak dapat dibenarkan dan diharapkan untuk tidak digunakan dalam kegiatan penebangan, dan seharusnya diperbaiki pada standar yang sudah ditentukan.

Kata kunci: Chainsaw, HTI, kelayakan, K3, HTI, penebangan.

\section{PENDAHULUAN}

Pekerjaan bidang kehutanan merupakan salah pekerjaan yang memiliki risiko tinggi untuk terjadinya kecelakaan kerja. Hal ini juga didukung dalam international labour organization (ILO) 2004, yang menunjukkan bahwa rata-rata kematian akibat kecelakaan kerja tertinggi di dunia berada pada sektor pertanian, kehutanan, pertambangan dan kontruksi. Kecelakaan kerja merupakan suatu kejadian yang tidak diinginkan yang menimpa pekerja di lingkungan kerja dan menimbulkan terganggunya proses produksi, serta menimbulkan kerugian fisik maupun non fisik bagi pekerja dan perusahaan (Yovi dan Syuaib 2016). Bahkan yang lebih parah dari terjadinya sebuah kecelakaan kerja adalah hilangnya nyawa pekerja tersebut dalam aktivitas bekerja.

Pemanenan hutan merupakan salah kegiatan pengelolaan hutan di Indonesia yang direncanakan sebaik mungkin berlandaskan pada aspek ekonomi, teknis, ekologi, sosial dan budaya. Perencanaan tersebut dirancang sedemikian rupa agar pelaksanaannya memberikan dampak yang baik bagi lingkungan serta memperoleh keuntungan ekonomi yang maksimal. Namun demikian, sering ditemui kejanggalan di dalam 
pengelolaan hutan. Dalam praktek pemanenan hutan, seringkali pengelola melupakan peran pekerja dalam kegiatan tersebut. Padahal, pekerja (manusia) berperan sebagai eksekutor dalam kegiatan pemanenan hutan dan memerlukan kompetensi dibidangnya. Sesuai dengan Kerangka Kualifikasi Nasional Indonesia (KKNI) dalam Keputusan Presiden Nomor 8 Tahun 2012 seorang pekerja harus memiliki sertifikasi kompetensi sebagai bukti yang menerangkan bahwa seseorang telah menguasai kompetensi kerja tertentu. Kompetensi yang wajib dimiliki seorang pekerja kehutanan khususnya dalam kegiatan pemanenan hutan adalah kompetensi dalam penebangan dan perlindungan $\mathrm{K} 3$.

Salah satu kegiatan pemanenan hutan yang memiliki resiko tinggi untuk terjadinya kecelakaan kerja adalah kegiatan penebangan. Beban kerja yang berat, lingkungan dan fisik yang tidak mendukung, serta penggunaan alat seperti chainsaw merupakan faktor penyebab terjadinya kecelakaan kerja (Yovi 2009). Gergaji rantai (chainsaw) merupakan alat penebangan yang pengelolaan hutan khusunya kegiatan

menggunakan mesin untuk menggerakkan rantai gergaji. Pada awalnya orang menebang atau memotong kayu dengan gergaji manual. Setelah mesin ditemukan maka mesin diaplikasikan pada gergaji untuk mendapatkan produktivitas yang tinggi.Pada saat ini chainsaw sudah mengalami puluhan modifi kasi bentuk dan aplikasi teknologi baru sehingga lahirlah chainsaw dengan teknologi mutakhir berupa lebih kecil dan lebih ringan serta putaran mesin yang sangat cepat (>15 rpm) (Pradipta 2016).

Oleh sebab itu perlu dilakukan identifikasi kelayakan mesin chainsaw yang digunakan oleh operator, khususnya pada PT. PSPI untuk mengetahui apakah operator chainsaw bekerja dengan menggunakan alat yang sudah sesuai dengan standar atau belum sesuai dengan standar. Hal ini merupakan salah satu upaya dalam mencegah dan mengurangi kecelakaan kerja dan penyakit akibat kerja pada kegiatan penebangan, dibidang kehutanan. Kegiatan pemanenan hutan yang memiliki resiko tinggi dipengaruhi oleh kombinasi beberapa faktor yang saling berkaitan satu dengan yang lain. Faktor yang saling berhubungan tersebut Ika Lestari, Emy Sadjati, Ambar Tri R., / Wahana Forestra: Jurnal Kehutanan Vol. 16 No. 02/2021 
adalah manusia, peralatan dan lingkungan kerja, manusia sebagai salah satu faktor penggeraknya merupakan satu satunya faktor hidup yang sangat rentan dengan bahaya kecelakaan. Namun juga merupakan salah satu faktor yang mampu meminimalkan kecelakaan kerja.

Adapun tujuan dari penelitian ini adalah untuk mengidentifikasi kelayakan mesin chainsaw yang digunakan oleh operator chainsaw di PT. PSPI. Hal ini untuk mengetahui apakah operator bekerja dengan alat yang sesuai dengan standar keselamatan dan kesehatan kerja. Dan juga merupakan upaya mencegah dan mengurangi angka kecelakaan kerja dibidang kehutanan. Masalah kecelakaan kerja khususnya dibidang kehutananan masih belum mendapatkan perhatian lebih jika dibandingkan dengan isu kehutanan lainnya, seperti isu kebakaran, illegal logging, deforestasi, degradasi hutan dan lain sebagainya. Kurangnya perhatian dan kesadaran terhadap perlindungan kesehatan dan keselamatan kerja merupakan salah satu masalah yang menyebabkan kecelakaan kerja di kehutanan sampai saat ini tidak sepenting Ika Lestari, Emy Sadjati, Ambar Tri R., / Wahana Forestra: Jurnal Kehutanan Vol. 16 No. 02/2021 isu kehutanan lainnya. Dalam UUD 1945 telah menetapkan bahwa setiap warga negara Indonesia berhak mendapatkan perlindungan dan penghidupan yang layak. Dan dalam undang-undang Republik Indonesia Nomor 13 tahun 2003 juga menegaskan bahwa perlindungan terhadap tenaga kerja dimaksudkan untuk menjamin hak-hak dasar pekerja/buruh dan menjamin kesamaan kesempatan serta perlakuan tanpa diskriminasi atas dasar apapun untuk mewujudkan kesejahteraan pekerja/buruh dan keluarganya dengan tetap memperhatikan perkembangan kemajuan dunia usaha. Begitupun dengan perlindungan dalam kecelakaan dan penyakit akibat kerja di lingkungan kerja adalah hak bagi pekerja yang wajib dipenuhi oleh pengelola dan perusahaan.

\section{METODE PENELITIAN}

Penelitian ini dilaksanakan di PT. PSPI Lipat Kain, Kabupaten Perawang Provinsi Riau. Dilaksanakan pada bulan Maret sampai dengan November 2020. Objek penelitian ini adalah operator chainsaw yang terlibat dalam kegiatan penebangan kayu di 
PT. PSPI Lipat Kain. Pengambilan sampel responden dilakukan dengan metode purposive sampling yaitu memilih sampling secara sengaja (dengan suatu kriteria tertentu) seorang individu untuk dijadikan contoh. Jumlah responden yang terpilih di lapangan sebanyak 19 orang dan merupakan operator chainsaw yang berada di lokasi kegiatan penebangan. Penelitian ini menggunakan dua teknik dalam mengidentifikasi kelayakan chainsaw yakni metode observasi dan wawancara.

a. Metode observasi

Metode ini menggunakan pengamatan pada fisik chainsaw yang digunakan oleh operator. Adapaun pengamatan yang dilakukan adalah:

1. Memeriksa kelengkapan komponenkomponen chainsaw baik body mesin dan komponen keselamatan (Lengkap/Tidak)

2. Memeriksa kebersihan mesin sebagai indikasi mesin chainsaw dirawat.

3. Mendokumentasi fisik chainsaw

Dari hasil observasi yang dilakukan akan diberikan skor penilaian terhadap pemeriksaan yang dilakukan yang merujak Ika Lestari, Emy Sadjati, Ambar Tri R., / Wahana Forestra: Jurnal Kehutanan Vol. 16 No. 02/2021 pada standar penggunaan chainsaw pada Buku Pintar Menebang Pohon Bagi Operator Chainsaw.

b. Metode kuisioner/wawancara

Metode ini digunakan untuk mengetahui kondisi chainsaw dengan memberi sejumlah pertanyaan kepada pemilik chainsaw (operator). Setiap pertanyaan pada kuisioner dijadikan sebagai informasi dan data dan megacu pada Buku Pintar Menebang Pohon Bagi Operator Chainsaw.

Penentuan kelayakan alat dalam penelitian ini menggunakan 4 indikator yang akan di observasi dan diteliti pada Tabel 1 dibawah ini.

Tabel 1. Indikator kelayakan mesin chainsaw

\begin{tabular}{clc}
\hline No & Indikator & Skor \\
\hline 1 & Tipe Alat & 20 \\
2 & Kondisi Alat & 30 \\
& a. Kebersihan dan keutuhan & 5 \\
& alat & 5 \\
& b. Kelengkapan komponen & \\
& alat & 5 \\
& c. Keutuhan mesin & 5 \\
& d. Kelengkapan & \\
& keselamatan kompomen & \\
& keselamatan & 5 \\
3 & e. Spare part & Modifikasi
\end{tabular}




\begin{tabular}{ccc}
4 & Umur alat & 20 \\
\hline & Total Skor & $\mathbf{1 0 0}$ \\
\hline
\end{tabular}

Tabel 2. Skoring penentuan tingkat kelayakan mesin chainsaw

\begin{tabular}{ccl}
\hline No & Selang & \multicolumn{1}{c}{ Keterangan } \\
\hline 1 & $90-100$ & $\begin{array}{l}\text { Mesin chainsaw sangat } \\
\text { layak pakai }\end{array}$ \\
2 & $80-89$ & $\begin{array}{l}\text { Mesin chainsaw layak } \\
\text { pakai } \\
3\end{array}$ \\
4 & $70-79$ & $\begin{array}{l}\text { Mesin chainsaw cukup } \\
\text { layak pakai } \\
\text { Mesin chainsaw Tidak } \\
\text { layak pakai }\end{array}$ \\
\hline
\end{tabular}

\section{HASIL DAN PEMBAHASAN}

\section{Tipe Alat Penebangan}

Sistem pemanenan kayu di Indonesia digolongkan berdasarkan jenis alat yang digunakan mulai dari alat manual, semi mekanis dan mekanis. Sistem manual, yaitu sistem pemanenan kayu yang dilaksanakan dengan menggunakan tenaga manusia, seperti sistem penyaradan di hutan rawa menggunakan tenaga manusia. Sedangkan sistem semi mekanis, yaitu sistem pemanenan kayu yang dilakukan dengan tenaga manusia namun dengan bantuan mesin-mesin pemanenan kayu, seperti penebangan pohon menggunakan chainsaw. Dan sistem mekanis, yaitu sistem pemanenan kayu dengan menggunakan mesin-mesin untuk pemanenan kayu, misal penggunaan alat berat harvester seperti feller buncher.

Sistem pemanenan kayu di HTI menggunakan dua sistem pemanenan yakni semi mekanis dan mekanis. Kolaborasi menggunakan dua sistem ini dinilai lebih efektif baik dalam produktivitas pemanenan kayu dan biaya operasional yang akan dikeluarklan oleh perusahaan untuk kegiatan pemanenan. Alat semi mekanis yang biasa digunakan adalah mesin gergaji rantai atau yang sering disebut dengan chainsaw yang mampu menebang, memotong dan membagi batang dengan bantuan manusia untuk mengoperasikannya. Sedangkan alat mekanis penebangan adalah harvester dengan tipe mesin bervariasi berdasarkan fungsinya yang mampu menebang,memotong, membagi batang, mengupas kulit batang dan membersihkan cabang dalam sekali kerja.

PT. PSPI merupakan salah satu anak perusahaan HTI di Provinsi Riau yang saat ini berproduksi pada hasil hutan kayu untuk bahan baku pulp dan paper, tanaman unggulannya adalah Ekaliptus dan Akasia. Kegiatan penebangan pohon di perusahaan 
ini juga menggunakan dua kolaborasi 2 sistem pemanenan, baik secara mekanis dan semimekanis untuk kegiatan penebangan kayu. Mesin chainsaw tipe STILH MS 381/382 merupakan alat yang digunakan

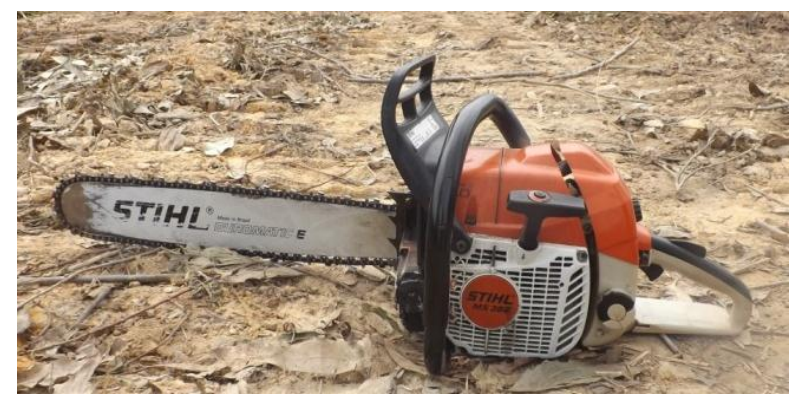

Gambar 1. Chainsaw merek STILH MS

Penggunaan mesin chainsaw dengan merek STILH MS 381/382 bukan tanpa alasan dipilih oleh operator chainsaw dalam kegiatan penebangan. Berdasarkan hasil wawancara yang diperoleh dari operator chainsaw bahwa chainsaw merek STILH MS $381 / 382$ ini relatif nyaman digunakan, tidak terlalu berat, mesin kuat dan bar tidak terlalu panjang sehingga sangat memudahkan pada saat proses penebangan kayu dengan diameter kayu 20-25 cm. Lebih spesifik terkait chainsaw merek STILH MS 381/382 pada Tabel 3. rata-rata oleh operator chainsaw di perusahaan. Dari 19 mesin yang digunakan operator diantaranya 17 menggunakan STILH MS 381/382 dan 2 lainnya menggunakan ECHO ( Gambar 1 dan 2).

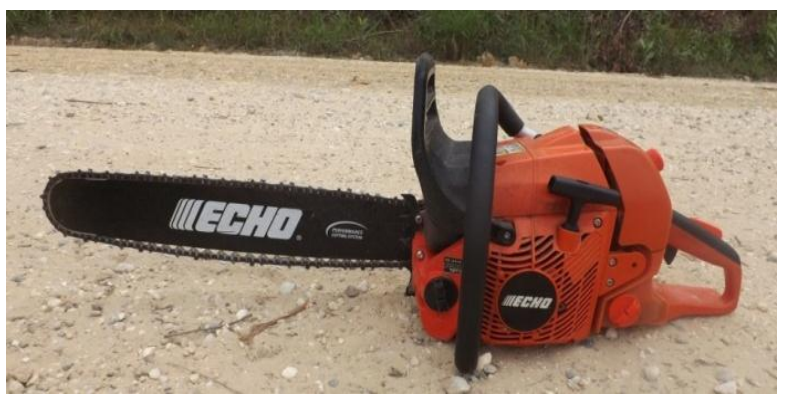

Gambar 2. Chainsaw merek STILH MS

Tabel 3. Spesifikasi MS STILH 381/382

\begin{tabular}{lll}
\hline \multicolumn{1}{c}{ Spesifikasi } & Keterangan \\
\hline Berat & $: 6.2 \mathrm{~kg}$ tanpa Bar & \\
Kekuatan mesin & $: 2$ Tak & \\
Isi silinder & $: 72,2 \mathrm{c}$ & \\
Sistem pengapian & $:$ Elektronik & \\
Kapasitas tangki oli & $: 0,36$ liter & \\
Kapasitas tangki & $: 0,68$ liter & \\
Bahan bakar & $:$ Bensin campur oli & \\
Panjang bar & $: 25$ / 63 cm & \\
Kecepatan maksimal & $: 13.5000 \mathrm{rpm} / 12.500 \quad \mathrm{r}$ \\
\multicolumn{1}{c}{ Berdasarkan } & Tabel. 3 diatas,
\end{tabular}
spesifikasi alat sangat sesuai dengan hasil wawancara dengan operator chainsaw. Tipe STILH MS 381/382 sangat mendukung untuk kegiatan kerja di penebangan. Khusunya pada 
jenis pohon dengan diameter kecil pada pohon Ekaliptus dan Akasia, dengan umur tebang kayu \pm 7 tahun dengan rata-rata diameter kayu tergolong kecil 20-25 cm sangat sesuai dengan panjang bar $63 \mathrm{~cm}$. Selain itu, kecepatan memotong kayu juga mendukung 12.5000-13.5000 rpm yang artinya kecepatan untuk memotong/merebahkan kayu sangat dibutuhkan. Serta berat chainsaw yang termasuk ringan $\pm 7 \mathrm{~kg}$ memudahkan operator untuk berpindah-pindah. Berdasarkan penelitian Hidayat et. al (2018) terhadap efisiensi prestasi kerja chainsaw Stihl MS 381 pada penebangan kayu mahoni sebesar 1,42 m3/jam atau 11,33 m3/hok dan prestasi kerja, lebih tinggi dibandingkan chainsaw STILH 070 sebesar 1,83 m3/jam atau $14,63 \mathrm{~m} 3 /$ hok.

Berbeda halnya dengan penebangan pada hutan alam dengan diameter kayu yang cukup besar $>40 \mathrm{~cm}$, dibutuhkan spesifikasi mesin chainsaw yang berbeda. Misalnya chainsaw STIHL 070 dengan spesifikasi: tenaga motor $6,5 \mathrm{hp}$, kecepatan maksimum $7500 \mathrm{rpm}$, berat alat tanpa bilah $10,7 \mathrm{~kg}$, kapasitas bahan bakar 1,2 liter, dan panjang bilah $90 \mathrm{~cm}$, spesifikasi alat ini sangat efektif dan efisien dalam meingkat produktivitas penebangan di Hutan TPTI di Kalimantan Timur dengan rata-rata diameter kayu $>40$ cm (Dulsalam et.al 2018). Pentingnya mengetahui produktivitas dari suatu alat juga menentukan jumlah alat yang dibutuhkan. Pada dasarnya perusahaan harus mampu menentukan spesifikasi alat penebangan seperti chainsaw dalam merencanakan penebangan, agar mengetahui jumlah alat yg dibutuhkan. Hal ini sesuai dengan penelitian Suhartana dan Yuniawati (2006) yang menyatakan bahwa penggunaan chainsaw yang efisien pada penebangan kayu harus disesuaikan pada rencana produksi dan potensi tegakan yang akan di panen.

\section{Kondisi Mesin}

Berdasarkan observasi dan identifikasi mesin chainsaw yang dilakukan di PT. PSPI diperoleh kondisi mesin yang digunakan oleh operator chainsaw dengan indikator sebagai berikut ini:

\section{Kebersihan alat}

Mesin chainsaw di lapangan berhadapan dengan berbagai material, seperti 
tanah, air dan serbuk kayu sisa bekas penebangan. Material-material tersebut jika dibiarkan dapat menyebabkan mesin menjadi rusak, karena komponen utama mesin terbuat dari besi yang sangat sensitif dengan berbagai material. Oleh sebab itu mesin harus dibersihkan setiap kali digunakan agar selalu kering dan terbebas dari material-material yang dapat merusak mesin. Berdasarkan hasil wawancara dan observasi langsung dengan operator chainsaw, keseluruhan operator chainsaw selalu membersihkan mesin setelah selesai penebangan. Kegiatan ini rutin dilaksanakan sebagai salah satu bentuk pemeliharaan harian dan bentuk pelaporan kepada supervisor di lapangan.

Bagian penting chainsaw yang perlu dibersihkan setiap kali penebangan adalah rantai mesin. Rantai chainsaw sangat mudah putus jika ada material-material pengganggu yang menyelip pada chainsaw sehingga sangat perlu untuk dibersihkan, seperti tanah, kerikil kecil atau serbuk bekas pemotongan kayu. Bekas oli juha yang merupakan sisa pembakaran dapat menimbulkan butiran hitam yang menempel pada chainsaw, ini juga perlu dibersihkan karena dapat menempel pada rantai dan dapat merusak rantai. Gambar 4 dan 5 dibawah ini contoh material yang harus dibersihkan pada mesin chainsaw. Gambar 4 bekas pembakaran pada mesin chainsaw meninggalkan serbuk warna hitam, apabila dibiarkan akan terbawa rantai mesin pada saat berputar dan masuk ke dalam oli, sehingga menyebabkan oli cepat kotor. Oli kotor tidak direkomendasikan untuk rantai mesin chainsaw, selain membuat mesin cepat panas juga menurunkan kinerja mesin. Gambar 5 menunjukkan material bekas penebangan pohon seperti kulit kayu, tanah, batu kerikil ataupun serbuk kayu yang menempel pada penangkap rantai. Dikhawatirkan jika dibiarkan membuat rantai terbelit dan putus saat kegiatan kerja berlangsung, serta membahayakan operator chainsaw pada saat bekerja. 


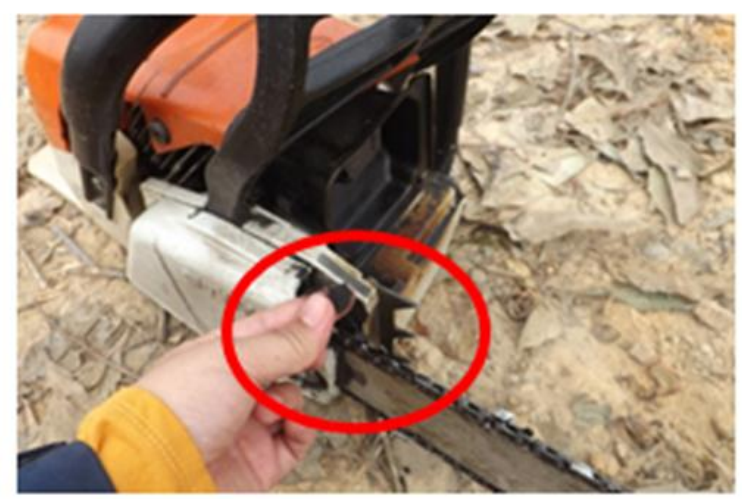

Gambar 3. Serbuk sisa pembakaran pada mesin chainsaw MS 381/382

\section{Kelengkapan mesin}

Saat mengoperasikan mesin, operator chainsaw berkewajiban memeriksa komponen-komponen pada mesin apakah masih berfungsi dengan baik atau tidak, serta komponen harus berada pada letaknya sesuai standar pabrik.

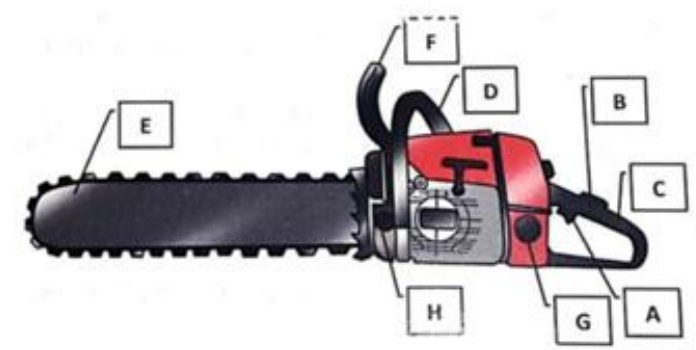

Keterangan: A (tombol gas), B (Pengaman tombol), C (Pegangan tangan kanan), D (Pegangan tangan kiri), E (Bilah/tempat rantai), $\mathrm{F}$ (Pengunci rantai), G (Tangki Bahan Bakar), $\mathrm{H}$ (Tangki pelumas)

Gambar 5. Komponen-komponen chainsaw lengkap (sumber foto: Buku pintar menebang pohon bagi operator chainsaw)



Gambar 4. Bekas kulit batang pada pohon tersangkut pada putaran chainsaw

Berdasarkan

observasi

dan pemeriksaan yang dilakukan dilapangan, komponen-komponen chainsaw yang dimiliki oleh operator chainsaw di PT. PSPI, keseluruhan mesin chainsaw masih dalam keadaan lengkap dan letak dan fungsinya sesuai dengan standar pabrik.



Gambar 6. Kondisi chainsaw di lapangan lengkap dengan komponen-komponennya 


\section{Keutuhan mesin}

Mesin chainsaw sering menghadapi hantaman material-material benda besar di lapangan, seperti log kayu yang besar. Hantaman tersebut sering kali membuat beberapa baut-baut pada mesin mulai goyang atau agak sedikit kendur atau pun lepas. Hal ini sebenarnya tidak boleh diabaikan karena akan membahayakan operator jika sewaktuwaktu pada saat mengoperasikan mesin ada bagian yang lepas. Mesin dalam keadaan sedikit goyang sangat mengganggu kenyamanan operator saat bekerja dan mengganggu kinerja operator. Oleh sebab itu operator harus rutin memeriksa dan mengencang baut-baut yang kemungkinan kendur, goyang ataupun lepas. Hasil wawancara dan pengamatan yang dilakukan dengan operator chainsaw kegiatan seperti mengaku bahwa mengencang baut-baut pada body mesin pada saat bekerja rutin dilakukan bersamaan pada saat operator membersihkan mesin. data aktual dan data hasil peramalan.

\section{Kelengkapan alat keselamatan pada mesin}

Mesin chainsaw dilengkapi alat pengaman yang berfungsi untuk melindungi operator chainsaw pada saat mengoperasikannya.

Diantaranya pengamaman tombol gas, rem rantai (chain break) dan handle pelindung tangan kiri (Gambar 5 dan Gambar 6). Komponen keselamatan pada mesin chainsaw. Pengaman tombol gas berfungsi untuk menjaga sewaktu-waktu pada saat mesin menyala tidak sengaja tersentuk atau tersenggol tidak menyebabkan rantai mesin berputar. Tombol gas dan tombol pengaman berrfungsi bersamaan, sehingga untuk menjalankannya harus ditekan bersamaan. Rem rantai berfungsi untuk menapkap rantai agar tidak berputar, sangat membantu operator chainsaw saat akan pindah lokasi tanpa harus mematikan mesin. Meskipun mesin dalam keadaan menyala dan tombol gas ditekan, rantai tidak akan berputar jika rem rantai berfungsi. Pegangan tangan kiri berada di dekat rem rantai berfungsi untuk melindungi tangan kiri pada saat mesin menyala. 


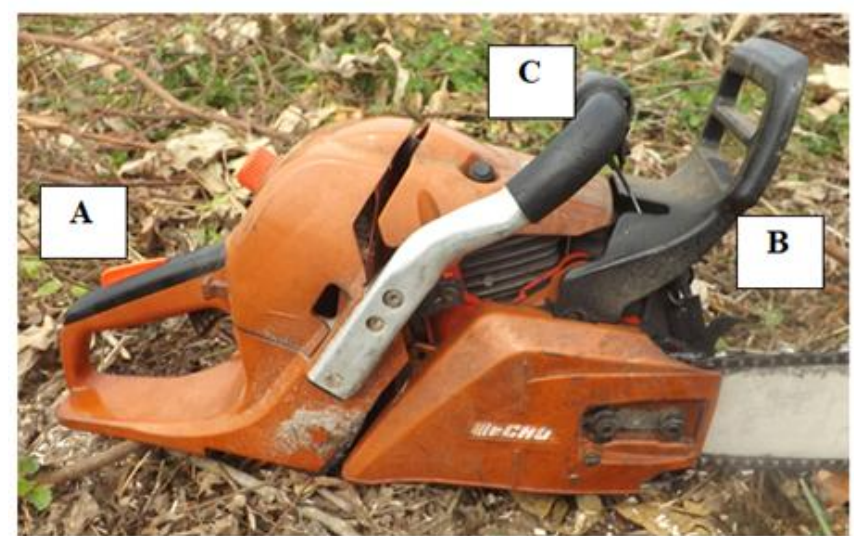

Gambar 7. Komponen keselamatan pada mesin

chainsaw

\section{Spare part}

Komponen-komponen chainsaw perlu diganti jika mengalami kerusakan atau sudah tidak berfungsi lagi dengan baik. Komponenkomponen yang diganti tersebut harus menggunakan suku cadang (spare part) yang asli sesuai dengan standar yang telah pabrik tentukan. Menggunakan suku cadang yang tidak asli dikhawatirkan manurunkan kinerja mesin, mesin cepat rusak dan harus diganti lagi. Spare part yang asli sesuai standar pabrik memang harganya lebih mahal, namun kualitasnya akan sangat menjamin performa mesin saat dioperasikan. Berdasarkan wawancara dan observasi dilapangan dengan operator chainsaw mengaku bahwa komponen mesin chainsaw mereka masih original standar pabrik, belum pernah bongkar pasang. Bagian yang paling sering diganti adalah rantai mesin, karena putus atau tidak tajam lagi.

\section{Modifikasi mesin}

Melakukan modifikasi pada bagian komponen dan mesin chainsaw sebenarnya bukan langkah yang tepat, karena mesin sudah disesuaikandengan standar yang telah ditentukan baik itu pada standar keselamatan. Selain itu, memodifikasi mesin juga membahayakan operator chainsaw jika komponen-komponen diubah letak dan fungsinya. Berdasarkan observasi dan wawancara di lapangan bersama operator chainsaw, 15 dari 19 mesin chainsaw yang 
digunakan oleh operator telah melakukan modifikasi knalpot (mesin pembuangan) pada mesin chainsaw. Hal ini dilakukan dengan alasan untuk meningkatkan performa mesin, ketika knalpot dibuka tekanan dan dorongan mesin semakin kuat dan meningkat. Hal ini tentu tidak bisa dibenarkan, dalam knalpot chainsaw terdapat alat penyaring pembuangan asap chainsaw. Jika dibiarkan sangat berbahaya bagi kesehatan operator chainsaw. Beberapa penyakit akibat kerja

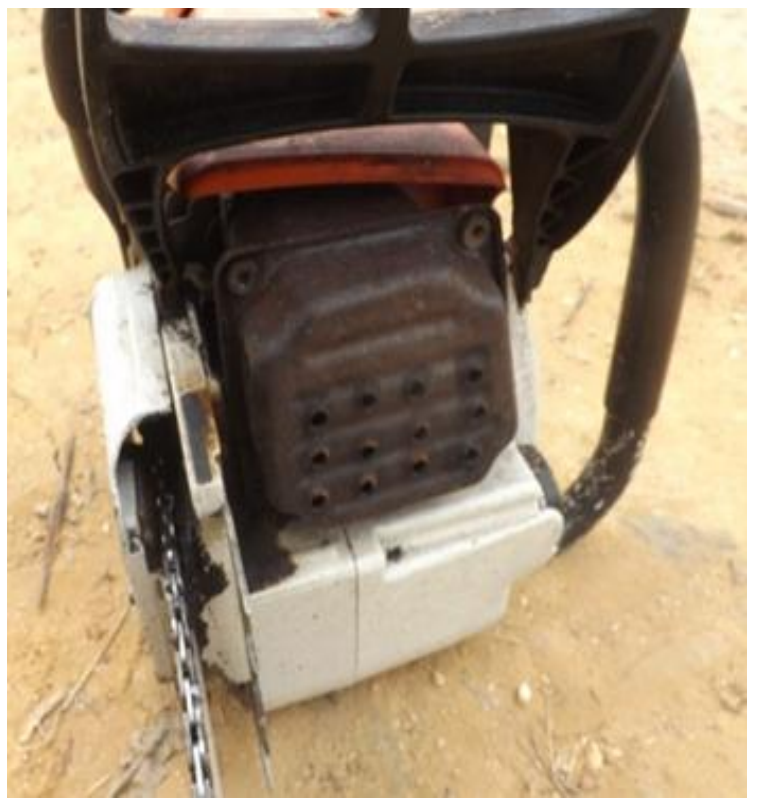

Gambar 8. Knalpot chainsaw sesuai standar menggunakan chainsaw diantaranya adalah gangguan pernafasan, gangguan pendengaran, gangguan otot dan gangguan pada saraf tangan (Yovi dan Suaib, 2016). Gangguan pernafasan disebabkan dari asap knalpot mesin chainsaw, jika alat dalam keadaan standar keselamatan saja bisa berisiko menyebabkan penyakit akibat kerja maka akan sangat berbahaya jika alat tanpa standar keselamatam dari hasil modifikasi.

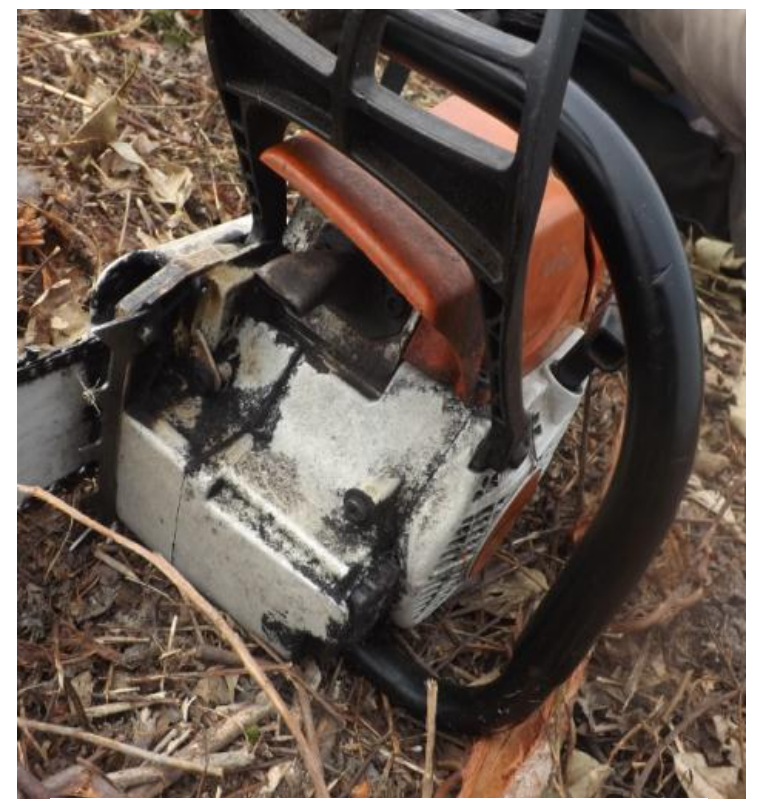

Gambar 9. Knalpot yang sudah dimodifikasi 


\section{Umur Alat}

Umur alat sangat memperngaruhi kondisi fisik, performa dan kinerja alat serta secara ekonomi akan menurunkan harga alat dari harga sebelum dibeli. Dalam penelitian ini umur alat dimaksudkan untuk melihat kondisi fisik alat dan pengaruhnya terhadap kinerja dan performa alat. Berdasarkan hasil wawancara, observasi dan identifikasi yang dilakukan dilapangan $81 \%$ operator chainsaw telah menggunakan mesin chainsaw miliknya 2 tahun lebih dan 19\% operator baru menggunakan kurang dari 2 tahun. Mesin tersebut tidaklah dibeli baru namun merupakan tangan kedua dari operator sebelumnya. Operator chainsaw lebih memilih sebagai tangan kerdua dikarenakan harga mesin akan sangat jauh lebih murah jika dibandingkan dengan membeli baru. Untuk menjamin mesin dalam keadaan bagus biasaya operator chaisaw dapat menelusuri riwayat pemakaian, perawatan dan pemeliharaannya. Hal ini dijadikan bahan pertimbangan bagi operator apakah akan membeli atau tidak. Jika dilihat dari umur alat berdasarkan tahun produksi mesin chainsaw STILH MS
381/382 merupakan mesin chainsaw keluaran tahun 2014 yang tahun ke tahun terus diperbaiki jenis dan performa mesinnya. Umur alat diduga berusia rata-rata 6 tahun dari tahun produksi 2014. Jika dilihat dari kondisi alat telah mengalami $35 \%$ penyusutan, dengan sisa umur ekonomis $65 \%$ artinya alat dalam kondisi baik (telah dipergunakan dan pernah dilakukan perbaikan, kondisi prima). Sedangkan merek lainnya ECHO masih tergolong sangat baik karena dalam keadaan baru dimana kondisi alat masih seperti baru, masih dipakai sebentar dan belum memerlukan penggantian suku cadang atau perbaikan.

\section{Kelayakan Alat}

Berdasarkan pengamatan dan observasi yang telah dilakukan dilapangan ada 4 indikator yang digunakan dalam metode untuk memutuskan apakah chainsaw yang digunakan oleh operator layak digunakan atau tidak yaitu tipe alat, kondisi alat, modifikasi dan umur alat. Hasil observasi dan pengamatan yang telah dilakukan, identifikasi mesin chainsaw yang dilakukan 
di PT. PSPI memiliki skor 70 masuk dalam kategori alat cukup layak digunakan (Tabel 5). Modifikasi pada knalpot mesin chainsaw tidak dibenarkan, sehingga skor diberikan nol. Meskipun pada kenyataannya alat memiliki performa mesin yang bagus, namun alat memiliki resiko penyakit dan kecelakaan kerja yang tinggi tetap tidak dibenarkan untuk digunakan oleh operator chainsaw.

Tabel 5. Indikator pengamatan dan observasi

$$
\text { di lapangan }
$$

\begin{tabular}{llc}
\hline No & \multicolumn{1}{c}{ Indikator } & Skor \\
\hline 1 & Tipe Alat & 20 \\
2 & Kondisi Alat & 30 \\
& $\begin{array}{l}\text { a. Kebersihan dan } \\
\text { keutuhan alat }\end{array}$ & 6 \\
& b. Kelengkapan & \\
& komponen alat & 6 \\
& c. Keutuhan mesin & \\
& d. Kelengkapan & 6 \\
& keselamatan & 6 \\
& kompomen & \\
& keselamatan & \\
& e. Spare part & \\
3 & Modifikasi & 6 \\
4 & Umur alat & 20 \\
\hline Total Skor & 70 \\
\hline
\end{tabular}

$$
\text { Identifikasi alat penebangan }
$$
seharusnya menjadi salah kegiatan yang rutin yang harus dilakukan di perusahaan. Kegiatan ini dapat direalisasikan dengan memeriksa secara rutin kondisi alat yang digunakan oleh operator pada saat akan memulai kegiatan penebangan. Identifikasi chainsaw ini merupakan upaya yang dilakukan untuk menurunkan laju kecelakaan dan penyakit akibat kerja di kegiatan penebangan, agar pekerja sehat dan aman setelah dan sesudah melakukan kegiatan kerja.

\section{KESIMPULAN DAN SARAN}

\section{A. Kesimpulan}

Penelitian identifikasi kelayakan mesin chainsaw dalam kegiatan penebangan yang dilaksanakan di PT. PSPI menggunakan 4 indikator yakni tipe alat, kondisi alat, modifikasi dan umur alat, yakni :

1. Tipe mesin yang digunakan oleh operator adalah STILH MS 381/382 dan ECHO, diantara 17 operator menggunakan STILH MS 381/382 dan 2 operator menggunakan ECHO.

2. Kondisi chainsaw yang digunakan operator dalam keadaan terawat, 
komponen lengkap baik komponen keselamatan serta menggunakan spare part orisinil.

3. Namun demikian 15 dari 19 alat chainsaw yang dimiliki operator telah melakukan modifikasi pada knalpot chainsaw dengan alasan untuk meningkat performa mesin. Hal ini tidak dibenarkan karena menghilangkan saringan asap knalpot di kahawatirkan membuat operator merasa tidak nyaman dalam bekerja dan berpeluang menimbulkan penyakit kerja seperti gangguan pernafasan.

4. Alat penebangan yang digunakan oleh operator chainsaw di PT. PSPI masuk dalam kategori cukup layak untuk digunakan dalam kegiatan penebangan dengan skor 70 . Modifikasi knalpot pada mesin chainsaw tidak dapat dibenarkan dan diharapkan untuk tidak digunakan dalam kegiatan penebanga, dan seharusnya diperbaiki dalam keadaan semula.

\section{B. Saran}

Perlu dilakukan penelitian lanjut dan pelatihan untuk meningkatkan pengetahuan operator chainsaw dalam merawat dan mengoperasikan chainsaw sesuai standard dan prosedur yang telah ditetapkan.

\section{UCAPAN TERIMA KASIH (ACKNOWLEDGEMENT)}

Ucapan terima kasih disampaikan kepada Lembaga Penelitian dan Pengabdiam Kepada Masyarakat, Universitas Lancang Kuning (LPPM UNILAK) atas dukungan dana yang diberikan dalam pelaksanaan penelitian ini melalui APBU tahun akademik 2019/2020, sehingga penelitian ini dapat dilaksanakan dengan baik.

\section{DAFTAR PUSTAKA}

Dulsalam, Sukardayati., Yuniawati. 2018.

Produktivitas, Efisiensi dan Biaya Penebangansilvikultur Intensif Pada Satu Perusahaan di Kalimantan Timur. Jurnal Penelitian Hasil Hutan. Volume. 36 (1): 1-12

[ILO] International Labour Organization. 2004. Keselamatan dan Kesehatan 
Kerja di Indonesia: Jakarta.

Lapau, Buchari. 2013. Metode penelitian kesehatan: Metode ilmiah penulisan skripsi, tesis dan desertasi. Yayasan Pustaka Obor Indonesia: Indonesia.

[KEMNAKER]. Kementerian Tenaga Kerja. 2003. Undang-undang Republik Indonesia Nomor 13 Tentang Ketenagakerjaan. Jakarta (ID): RI.

[PPRI] Peraturan Pemerintah Republik Indonesia. 2012. Penerapan sistem manajemen keselamatan dan kesehatan kerja (SMK3) nomor 50. Jakarta (ID): Indonesia.

Pradipta, Raditya Angga. 2016. Risk assessment pada pekerjaan menebang kayu di Hutan chainsaw Perum Perhutani KPH Madiun). The Indonesian Journal of Occupational Safety and Health. Volume 5(2): 153 162.

Salawati, Liza. 2015. Penyakit akibat kerja dan penecegahannya. Jurnal Kedokteran Syiah Kuala. Volume 15(2): 1-6.

Suhartana S, Yuniawati. 2006. Efisiensi penggunaan chainsaw pada kegiatan penebangan : Studi kasus di PT Surya Hutani Jaya, Kalimantan Timur. Pusat Litbang Hasil Hutan.

Yovi EY, Syuaib M Faiz. 2016. Buku Pintar Menebang Pohon Bagi Operator Chainsaw. Bogor (ID): IPB Press.

Yovi EY. 2009. Penilaian perlindungan kesehatan dan keselamatan kerja pada kerja kehutanan melalui pendekatan kompetensi. [diacu 20 Oktober 2013]. Tersedia dari: Media Majalah Ilmu Faal. Indonesia. Volume (8): 2. 